\title{
Comic-Book Superheroes and Prosocial Agency: A Large-Scale Quantitative Analysis of the Effects of Cognitive Factors on Popular Representations
}

\author{
James Carney ${ }^{1}$ and Pádraig Mac Carron ${ }^{2}$
}

Department of Experimental Psychology, University of Oxford, UK

\section{Introduction}

Though popular culture has started to come within the purview of cognitive science (Clasen, 2012; Jarett, 2011; Salmon, 2005; Zunshine, 2011, 2012), it has yet to profit from the sustained research programmes that have been devoted to other practices — chief among them, religion - that are concerned with human fabulation. This is regrettable, because many of the same features that recommend religious phenomena for cognitivist analysis are present in popular culture, too. Specifically, just as religious concepts illustrate cognitive biases in virtue of their not being constrained by real-world objects (Atran \& Norenzayan, 2002; Barrett \& Nyhof, 2001; Boyer \& Ramble, 2001), the representations of popular culture frequently deal with counterfactual entities and worlds that are intuitively coherent without being physically plausible. Moreover, it can be argued that, in much the same way that religious representations percolating through large populations drift towards cognitive optima (Boyer, 1999; Morin, 2012; Sperber, 2006), those non-religious representations that conform to these optima will be equivalently selected for by processes of cultural reproduction. Thus, if the task involves identifying how cognitive constraints interact with historical

\footnotetext{
${ }^{1}$ Corresponding author: james.carney@psy.ox.ac.uk

2 padraig.maccarron@psy.ox.ac.uk
} 
circumstances to generate cultural representations, then popular culture offers a useful—and largely unexploited — reservoir of examples, problems and potential insights.

Proceeding from these considerations, we investigate here how one genre of popular culture - comic-book literature-reproduces human intuitions about sociality in response to historically specific circumstances. Our motivation for dealing with this specific topic in comes from a previous study, in which we claimed that the emergence of comic-book fiction can be understood (at least in part) as a response to the cognitive demands of large-group sociality (Carney, Dunbar, Dávid-Barrett, Machin, \& Júnior, 2014). That is, we argued that human beings have cognitive resources for dealing with groups up to a certain size, and when group cardinality exceeds this size, cultural prostheses like comic-book literature come into play that negotiate the difference between human circumstances and human ability. We summarise this hypothesis in more detail in the pages following, but its main outcome was to deliver four predictions: comic-book superheroes should (i) exhibit punitive prosociality, (ii) be quasi-omniscient, (iii) display kin-signalling proxies and (iv) be minimally counterintuitive. Essentially, these predictions identified the likely outcomes of cultural processes designed to resolve the problems that emerge when group size gets too large - most notably, issues concerned with identifying reliable cooperation partners and inhibiting antisocial actions.

In the previous study we gauged these four predictions against a small sample of 16 superheroes and found sufficient qualitative confirmation to justify further testing; here, we present the results of this testing by showcasing what emerged from a large scale quantitative survey of 19,877 characters in 72,611 individual comics. As might be expected, data on this order of magnitude cannot be analysed in any realistic timeframe by individual researchers, so we proceeded by using automated data scraping techniques to assay the wiki databases for both Marvel and DC publishers. As repositories for user-generated summaries of individual 
comics, these wikis crowd-source the problem of surveying large bodies of qualitative data; thus, they enable forms of analysis that would be impossible using the methodologies of standard textual scholarship. Admittedly, this increase in scope is offset by a diminution in precision when it comes to the material analysed. Nevertheless, we suggest that the results gained offer an extremely valuable quantitative perspective in a field where such perspectives are often lacking, and that this readily compensates for any loss of interpretive nuance.

One final point is in order before proceeding to the details of our analysis. Though studies of popular culture have gained a great deal of credibility in the last number of decades, comic-book materials often remain subject to an "acid moralism" (Eco, 1972, p. 21) that sees them as little more than rude distractions for jejune sensibilities. As we lack the sophistication to adjudicate such lofty claims, we shall not attempt to do so; however, we do argue that it would be peremptory to let the (perceived) triviality of the material stand in the way of its analysis. In particular, the extent to which comic-book representations motivate their audience into forms of collective identity is quite remarkable, and has generated a substantial scholarly literature (Brown, 1992; Harris \& Alexander, 1998; Kleefeld, 2009; Wright, 2001). Given this, we submit that any attempt to penetrate into the cognitive provenance of comic-book literature will reward the undertaking by delivering insights into how (and why) counterfactual representations should so arrest the collective attention of modern audiences.

\section{The cognitive problem of large groups}

The investigation of how social groups cohere is a well-established topic in the socialscientific and psychological literature. On the practical side, studies have focused on how group coordination is achieved by way of (for instance) musically mediated synchronous 
movement (Hove \& Risen, 2009; Launay, Dean, \& Bailes, 2013), religious display and ritual (Sosis, 2004, 2005; Whitehouse, 2004), group storytelling and narration (Bhaba, 1990; Dissanayake, 2000; Somers, 1994) and the sharing of gossip (Dunbar, 1996). This, in turn, has led to theory driven investigations of the properties of real-world social networks (Bilke \& Peterson, 2001; Newman \& Park, 2003; Usdiken \& Pasadeos, 1995) and fictional networks (Mac Carron \& Kenna, 2012, 2013) as well as innovations like agent-based modelling, which simulate the effects of changing network parameters on group action (Dávid-Barrett \& Dunbar, 2012, 2013; Gould, 1993; Siegel, 2009). In their different ways, all of these approaches offer useful contributions to the understanding of how groups - and especially large groups — succeed in organising themselves towards collective ends.

Nevertheless, while the behavioural aspects of group cohesion have benefitted from existing research traditions, the same is not true for the cognitive problems thrown up by large-group sociality. For the fact is, the difficulty of assorting in large groups is not just a practical problem, but an intellectual one, too. In particular, it has been consistently shown that violations of ontological, linguistic or social expectations act as a spur for recuperative cognitive activity that seeks to integrate the violation with existing knowledge (Berlyne, 1970; Bettencourt, Dill, Greathouse, Charlton, \& Mulholland, 1997; Fauconnier \& Turner, 2002; Lévi-Strauss, 1955; Sperber \& Wilson, 1995; Sperber, 1975). On the surface, this may not seem to have much relevance for the issue of large groups, given that expectation violations tend to be categorical in character when increased group size offers merely quantitative variation. However, this ignores the possibility that humans may have an optimal group size that is reflected in the cognitive architecture that they have evolved to deal with group sociality. If so, then there may be a discrete threshold such that, when group size exceeds it, the latter becomes cognitively salient as a target for explanation. The questions 
that emerge from this concern, firstly, whether such a threshold actually exists; and secondly, in the case that it does, if social circumstances consistently challenge it.

In the first regard, the 'social brain' hypothesis suggests that the relatively larger neocortex size in primates (and the variation of neocortex size within primates) is driven by the demands of group sociality (Byrne \& Corp, 2004; Dunbar \& Shultz, 2007; Dunbar, 1992, 1998; Humphrey, 1976). The logic behind this claim is that linear increases in group size result in a non-linear increase in the number of possible relationships within a group; thus, associating in large, structured groups requires substantially increased processing power (Dávid-Barrett \& Dunbar, 2013)—and hence the selection for a larger neocortex in primates. For humans, viewing neocortical volume through this lens predicts that the optimal group size should consist of approximately 150 individuals (Dunbar, 1993). As this figure will be mediated by local circumstances, it is likely to exhibit large variance; but informed estimates of optimal network size in humans nevertheless oscillate between 100 and 200 connections (Gonçalves, Perra, \& Vespignani, 2011; Hamilton, Milne, Walker, Burger, \& Brown, 2007; Hill \& Dunbar, 2003; Killworth, Bernard, \& McCarty, 1984; Zhou, Sornette, Hill, \& Dunbar, 2005). Indeed, even if one disagrees with the $\sim 150$ estimate, most dissenting assessments remain on the same order of magnitude, to the extent that even the most charitable definition of what comprises a network member results in ego-centred networks of no larger than 1,000 (Wellman, 2012). Correspondingly, it would seem that the human capacity for sociality has relatively low ceiling, even if opinions differ as to where, exactly, this ceiling might be.

The second question — whether real social circumstances regularly push human beings above their cognitive ceiling - is more easily answered. Though human beings have associated in cities since at least 4,000 BCE, it was only with the industrial revolution that the city became the dominant form of sociality (Williamson, 2002). Moreover, contemporary developments have seen this trend accelerate dramatically, with current estimates suggesting 
that $54 \%$ of the global population now lives in cities (United Nations, 2014).

Correspondingly, if there does exist a basic limit on the size of human networks, then contemporary social life will consistently make this salient by exposing individuals to strangers - and by implication, to the threats and problems that emerge when network monitoring fails. In other words, where small networks allow punishment to be matched to infractions relatively easily — mostly, by allowing for the quick identification of malefactors - large networks make it difficult, if not impossible, to establish reciprocative relations with all the individuals that one regularly encounters. Thus, contemporary urban life foregrounds the problems of free riding and active hostility in a particularly acute way.

It is here that our central claim comes into play. If, as previously suggested, the frustration of schematic cognition acts as a cognitive prompt, then the failure of social cognition to meet the demands of social circumstance will likely foreground large group size as a stimulus for cognitive activity. Specifically, group sizes larger than those that human cognitive architecture has evolved to deal with will announce themselves as problems that, in one way or another, need to be solved. Moreover, the literature suggests that this processing will not just focus on practical solutions, but will also look the fictional and symbolic solutions that can be attached to the problem. Thus, it can be seen how the problem of large-group sociality might prompt sustained attempts to render it cognitively tractable in the cultural sphere. As no practical solution is likely to wholly resolve the problem of large group sociality (even if institutions like religion may help alleviate it), it is likely that the most effective way of relieving the cognitive anxiety it engenders comes with tackling the problem in the counterfactual domain. That is, by constructing a relatively low-cost fictional world that has been minimally altered so as to not contain the problem of large group sociality, one simultaneously dissolves the problem while retaining a degree of verisimilitude that makes the dissolution appropriate to real-world circumstances. Inevitably, such a compromise can 
only be temporary, given that it can never actually resolve the challenges posed by large groups. However, this also means that the sociality problem remains active as an ongoing stimulus for counterfactual fabulation, to the extent that it simultaneously invites and refuses solution. So what might this fabulation look like in practice?

Enter comic-books. Though we certainly do not suggest that comic-books are the only way in which the large-group problem can be cognitively and culturally tackled (see Carney (2014) for a discussion of detective fiction in this connection), a prima facie case can be made that they are centrally concerned with issues of network monitoring. As explored in our previous paper on the topic, the subject matter of comic books focuses on the violation and restoration of social norms, usually by way of criminality and its punishment. In itself, this is unremarkable: every narrative, in one form or another, is initiated by a breach in existing states of affairs and is propelled by the need to repair it (Bruner, 1991). Nevertheless, if comic-books can be understood as an attempt to resolve the problem of large group sociality in the counterfactual sphere, then their content should exhibit identifiable, recurrent features. In Carney, Dunbar, Dávid-Barrett, Machin, \& Júnior (2014), this claim was phrased in terms of four predictions, which we shall now briefly recapitulate.

\section{The four predictions}

Given that the problems of large group sociality are relatively well-understood, we should be able to predict the form that fictional solutions of this problem are likely to take. This means making predictions concerning the principal innovation of the comic-book genre, which is the figure of the superhero. Inevitably, the cultural salience of the superhero figure means that these predictions cannot be made in a vacuum. The point, however, is less to arrive at novel statements about the subject matter than it is to offer testable hypotheses concerning the 
regularities that it exhibits. In this regard, we predict that, in the case that comic-book fiction seeks to resolve the problems posed by large groups, it should evince the following four characteristics:

1. Superheroes should be punitively prosocial. The background to this prediction comes from the extensive ethnographic, experimental and theoretical literature on third-party punishment, which suggests that an evolutionary advantage attaches to the propensity to invest resources in punishing wrongdoers even when the punisher has suffered no harm - a behaviour that has been observed in animal as well as human networks (Bendor \& Swistak, 2001; Fehr \& Fischbacher, 2004; Flack, Girvan, de Waal, \& Krakauer, 2006; Henrich et al., 2006; Sigmund, Hauert, \& Nowak, 2001). The logic here is that the expectation, on the part of wrongdoers, of disinterested punishment from all agents permanently disincentivises wrongdoing, whereas expecting punishment from injured parties exclusively merely offers a partial disincentive. Thus, third party punishment stabilises reciprocative norms by discouraging self-interested defections from dyadic relationships. In real-world scenarios, third party punishment is obviously limited in its scope by practical concerns - not least among these being the costs to the punisher, which increase with each addition to the network. In fact, work by Pedersen, Kurzban, \& McCullough (2013) suggests that subjects consistently predict that they will engage in third-party punishment to a greater extent than they actually do. This latter point is important, because it highlights how hyper-punitive figures might emerge with particular emphasis in fictional representations, where the desire to punish can be exercised without the cost. Thus, if increasing potential network size beyond intuitive limits exposes one to more instances of free riding and active malfeasance, then one temporary solution to this problem comes with creating 
counterfactual worlds that include hyper-punishers-i.e. individuals whose propensity for third-party punishment exceeds ordinary human norms. While this does not solve the practical problem of network policing, it does at least offer an intellectual response to the motivating issues. We propose that superheroes are defined by this hyper-punitive role, and that exploring whether or not they exhibit more punitive behaviour than other prosocial agents can test our claim.

2. Superheroes should be quasi-omniscient. Research on cross-cultural features of religious representations have picked out "privileged epistemic access" (Bering \& Johnson, 2005, p. 120) as a trait repeatedly assigned to supernatural agents. That is, supernatural agents are imagined as having direct access to mental states — access that they use to morally monitor the self's thoughts and actions. This, it is argued, disincentivises the breaking of social norms by encouraging the subject to believe that all their actions are witnessed by invisible agents who may also be punitive in nature - a claim that has come to be known as the 'fear of supernatural punishment hypothesis' (FSPH). Both experimental and ethnographic evidence suggests that the FSPH picks out a psychological tendency that is cross-cultural in its distribution (Atkinson \& Bourrat, 2011; Bering \& Johnson, 2005; Bourrat, Atkinson, \& Dunbar, 2011; Johnson \& Krüger, 2004; Piazza, Bering, \& Ingram, 2011). The relevance of this for large group sociality should be clear: a universal belief in morally concerned, omniscient agents allows for increased network size by disincentivising self-interested actions that might otherwise be performed when the chance of actual detection is slight. Again, no actual agent can exhibit these traits, so a counterfactual solution to the large group problem will likely involve the postulation of agents-like supernatural beings - that are omniscient or quasi-omniscient. ('Quasi,' in this 
connection, is intended to cover instances where the omniscience achieved through naturalistic means like technology, as well as by way of explicit supernatural abilities.) Following these ideas, we suggest that, relative to other sub-populations of comic-book characters, superheroes should exhibit greater degrees of quasiomniscience.

3. Superheroes should exhibit kin-signalling proxies. The use of fictive kin relations to extend social network size is a well-documented phenomenon (Carlos, 1973; Carsten, 2000; Chatters, Taylor, \& Jayakody, 1994; Ibsen \& Klobus, 1972; Lakoff, 2002). For the most part, this is explained using the principles of kin selection: if one subordinates reliable, non-kin co-operators to the kin category, then monitoring costs are reduced and the network can be correspondingly extended (Hamilton, 1964). Equally, there is evidence from game theory that exhibiting kin-like behaviours (that is, treating one's neighbours as if they are kin) successfully eliminates invasive alternative strategies if collectively pursued (Eshel, Sansone, \& Shaked, 1999). Thus, hypothetical kinship can play a major role in consolidating and advertising an individual's reliability as a cooperation partner. This feature of social life can pay obvious dividends when it comes to extending network size, principally by allowing for a wider range of individuals to be incorporated at lower cognitive cost. Correspondingly, we would expect to see counterfactual solutions to the large group problem exploit this possibility—most likely, by both assigning fictive kin status to prosocial punishers and having these punishers exhibit kin-like behaviour. This yields our third prediction: Superheroes should exhibit higher levels of kin-signalling than that displayed by other groups. 
4. Superheroes should be minimally counterintuitive. Our fourth prediction has less to do with the issue of sociality and more to do with that of memorability. Specifically, even if comic-book fiction does engage with the problems posed by large group association, the solutions it offers are unlikely to be effective unless they are culturally salient. In practice, this means that superheroes should be memorable. Extant ethnographic and experimental work on religious representations suggests that one way of achieving memorability is to this is to make representations minimally counterintuitive (Atran \& Norenzayan, 2002; Atran, 2002; Barrett \& Reed, 2011; Boyer \& Ramble, 2001; Boyer, 2001; Norenzayan, Atran, Faulkner, \& Schaller, 2006). The idea here is that concepts and representations that differ minimally from existing prototypes are more memorable than instances of either the prototype itself or major violations of the prototype. Thus, the notions of a large rock and a rock that's an in-law of a Habsburg monarch and has $57.67 \%$ timeshare on the colour green are both less memorable than the notion of a singing rock. By analogy, we predict that the most popular superheroes should be ones that are minimally counterintuitive with respect to conventional ontological categories.

\section{Methods}

We evlauated the four predictions against the user maintained databases for DC Publishing (dc.wikia.com) and Marvel Comics (marvel.wikia.com). Though these resources are not authoritative in the sense of being monitored by the relevant publishers, they are peer-edited and thus frequently checked for errors. The material on the databases consists of character pages (which summarise the characteristics of individual characters) and comic pages (which summarise specific editions). A Python script was written to download all character pages 
(DC: 15,549; Marvel: 39,486) and comic pages (DC: 41,939; Marvel: 41,540) in the form they had in early September 2014. Information on a character's main alias and their number of powers and abilities was scraped from their character page. (Largely incomplete or empty pages were ignored; this meant that we did not use all the total number of character or comic pages we originally downloaded.) Different versions of each character were merged into one: for instance, the Bruce Waynes from New-Earth, Earth-1, Earth-2 and so on were all treated as 'Bruce Wayne.' The most commonly occurring alias was chosen as a given character's alter-ego (but only if the alias contained no parts of the character's name; otherwise they were treated as having no alter-ego). The number of powers and abilities possessed was averaged over the number of incarnations each character had. For every comic, the names of the specific characters that appeared in it were tabulated. All of this generated a list of characters that recorded their appearances, associations, capacities and prosocial orientation in a way that could be picked according to needs of each analysis.

An important methodological issue arose with respect to identifying whether or not a prosocial character counted as a superhero. Given that we were working from a set of predictions concerning the essential features of superheroes, we could not, without circularity, use these predictions to pick out the relevant population. Instead, we needed a trait that was not linked to our predictions, but was still reliably correlated with superhero characters. For this, we chose to use the traits of (i) possessing an alter-ego and (ii) not being a villain as the criteria of being a superhero. On the one hand, this allowed us to discriminate between superheroes and ordinary heroes; on the other, it obviated the need to manually inspect the data, given that each character page listed the alter-ego of each featured character. Nevertheless, it did mean that characters that were intuitively identifiable as superheroes but did not exhibit an alter-ego (e.g. Phantom Stranger, Thor, Jor-El) were listed under the category of ordinary heroes. Though this increased the possibility of Type II errors, results 
justified this decision by still exhibiting significant differences between populations in spite of the conflation. In terms of the populations themselves, we partitioned the characters into four categories: superheroes (prosocial agents with an alter-ego), heroes (prosocial agents without an alter-ego), supervillains (antisocial agents with an alter-ego) and villains (antisocial agents with no alter-ego).

Statistical tests concerning these populations were carried out in accordance with the nature of the question being asked. Given that the data were not normally distributed, this meant that non-parametric analogues to the $t$ test and one-way ANOVAs were used (respectively: the Mann-Whitney and the Kruskal-Wallis tests). As is usually the case with non-normal data, medians and interquartile ranges $(I Q R)$ were reported instead of means and standard deviations. All tests were carried out twice: firstly, with reference to the entire population of characters; and secondly, with reference to the top 100 characters in each subpopulation as determined by appearance (50 from Marvel, 50 from DC). In any given analysis, our $\mathrm{N}$ varied due to the fact that not all members of the population were relevant to the prediction being tested. Analysis was performed using custom Python scripts and SPSS version 21 .

\section{Results}

Prediction 1: Superheroes should be punitively prosocial. This prediction was tested by comparing the two prosocial populations of superheroes and heroes (i.e. those with and without an alter-ego). Because levels of punitive prosociality cannot be measured directly, we took the median number of villains encountered per appearance in a comic as a proxy measure. (This also avoided the problem posed by simply summing the total amount of villains encountered over a character's history, which results in long-running characters like 
Batman and Spider-Man encountering vastly more villains than anyone else simply in virtue of featuring in more stories.) For the entire population of usable superheroes $(N=1,775)$, this yielded a median of $3.06(I Q R=2.21)$; for the entire population of usable heroes $(N=824)$ the median number of villains encountered was $2.19(I Q R=2.17)$ (figure 1). A MannWhitney $U$-test was conducted to evaluate the hypothesis that superheroes would encounter more villains per appearance than heroes. The results of the test were in the expected direction and significant, $z=-7.41, p<.001$. An equivalent exercise was then performed for the top 100 characters as determined by frequency of appearance. This gave a superhero median of $3.46(I Q R=0.82)$ and a hero mean of $2.7(I Q R=13)$ (figure 2). Again, the results of significance testing were in the expected directed and significant, $z=-5, p<.001$. Thus, our prediction that superheroes would exhibit higher levels of punitive prosociality than other prosocial populations was borne out by both analyses.

Prediction 2: Superheroes should be quasi-omniscient. On the interpretation offered here, omniscience corresponds to a character having privileged access to the actions and mental states of others. However, connecting this definition to the nature of the data required that two problems be overcome. Firstly, given that quasi-omniscience can be implemented in an extremely large number of ways, there is no method of exhaustively cataloguing its presence without manually inspecting all relevant characters in their every appearance. As this was unfeasible, we chose to use network connectedness - understood as the number of coappearances with another character - as a proxy for omniscience. This is because knowledge of a character's actions almost invariably leads to association with that character in comicbook narratives; thus, it shows up the extent to which an agent is implicated in the actions and thoughts of others. Nevertheless, this led to the second problem: while each wiki page records the inventory of characters in a given comic, it does not record their interactions. We chose to 
resolve this by assuming that any characters who had an independent wiki page would plausibly have interacted.

Starting with the entire population of characters, initial results yielded median levels of connectedness of 23 for superheroes $(N=6,946, I Q R=83), 12$ for heroes $(N=9,830, I Q R=$ 29), 207 for supervillains $(N=552, I Q R=340)$ and 137.50 for villains $(N=426, I Q R=241)$ (figure 3). A Kruskal-Wallis test was used to evaluate the hypothesis that superheroes would be hyper-connected relative to the other three categories; this yielded a significant result, $H$ $(3)=2061.07, p<.001$. Post hoc pairwise comparison showed that all populations were significantly different from one another. However, while the direction of the difference was as expected for the prosocial popoulation groups (superheroes were more connected than heroes), results showed that the antisocial groupings of villains and supervillains were, by a large margin, more connected than the prosocial groups. This unexpected result contrasted markedly with that obtained from analysing the top 100 characters. Here, the median levels of connectedness were 1,438 for superheroes $(I Q R=614), 608$ for heroes $(I Q R=386), 617.50$ for supervillains $(I Q R=293)$ and 435.50 for villains $(I Q R=307)$ (figure 4). A KruskalWallis test showed that there were statistically significant differences between these populations, $H(3)=209.17, p<.001$. Post hoc pairwise comparisons indicated that, with the exception with the exception of heroes and supervillains, all populations differed significantly and in the predicted direction. This showed that, while the population as a whole did not match our predictions, the most popular representations were hyper-connected relative to other groups - and thus they can be plausibly identified as exhibiting greater levels of quasiomniscience.

Prediction 3: Superheroes should exhibit kin-signalling proxies. Any metric capable of capturing quasi-kin relationships needs to be sensitive to the fact that they can take many 
forms (quasi-fraternal, quasi-avuncular, quasi-parental and so on). Thus, rather than try to enumerate all of these forms in advance (which would require manual coding), it is probably more efficient to identify a common core to all possible types of quasi-kin association. We did this by taking repeated pairings with regular partners as a proxy for kin-signalling. That is, we assumed that the persistent pairing of characters indicated a relationship of cooperation, and that the greater the degree of this association, the more it approximated to a quasi-kin bond. Naturally, because cooperative association can only occur between characters that have the same social orientation (i.e. prosocial or antisocial), we did not include dyads containing members of both the hero and villain classes in our analysis. (We also collapsed the classes of 'villains' and 'supervillains' into each other for computational convenience.) Our measure of repeated pairing was achieved by counting the amount of times two characters appeared together, and dividing by the total number of appearances of the lesser appearing character. If this delivered a value of exactly one, then it implied that the lesser character only appeared in the company of the greater character, and thus their dyad had the strongest possible interaction strength. Values of less than one, by implication, measured the degree to which dyad's partners appeared independently of each other. We only performed the analysis of interaction when both characters had separate wiki pages, so as to avoid the inflated measures of association that would emerge when once-off characters were included.

The analysis divided the population of characters into relevant classes of dyads: superhero-superhero (SH-SH), superhero-hero $(\mathrm{SH}-\mathrm{H})$, hero-hero $(\mathrm{H}-\mathrm{H})$ and villain-villain $(\mathrm{V}-\mathrm{V})$. Surveying all occurent dyads in our data gave a median interaction strength of 0.13 for SH-SH $(N=95,084, I Q R=0.3), 0.28$ for SH-H $(N=124,970, I Q R=0.7), 0.5$ for $\mathrm{H}-\mathrm{H}(N$ $=42,703, I Q R=0.83)$ and 0.06 for $\mathrm{V}-\mathrm{V}(N=15,041, I Q R=0.11)$ (figure 5). A KruskalWallis test was used to evaluate the hypothesis that superheroes would exhibit greater kinsignalling proxies (by way of interaction strength) than other populations; it showed that 
statistically significant differences existed, $H(3)=28,221.74, p<.001$. Post hoc pairwise comparison showed that all combinations of population type were significantly different from one another. Nevertheless, the highest interaction strength was not exhibited by either SH-SH or $\mathrm{SH}-\mathrm{H}$; instead, against our prediction, $\mathrm{H}-\mathrm{H}$ gave the highest interaction strength, followed in declining order by SH-H, SH-SH and V-V. For the top 100 characters, on the other hand, testing showed dyads to have a median interaction strength of 0.39 for $\mathrm{SH}-\mathrm{SH}(I Q R=0.1)$, 0.02 for SH-H $(I Q R=1), 0.01$ for $\mathrm{H}-\mathrm{H}(I Q R=0.04)$ and 0.03 for $\mathrm{V}-\mathrm{V}(I Q R=0.05)$ (figure 6). A Kruskal Wallis test indicated that all dyads were significantly different, $H(3)=250.53$, $p<.001$. Here, the SH-SH dyad had the highest interaction strength, followed by SH-H, V-V and $\mathrm{H}-\mathrm{H}$ in that order. Correspondingly, though the entire population of dyads did not match our predictions, the 100 most popular characters once again confirmed them.

Prediction 4: Superheroes should be minimally counterintuitive. This prediction entails that superheroes should (i) have more traits that distinguish them from the category of 'person' than either heroes or villains, but less than supervillains; and (ii) that the number of minimally counterintuitive superhero traits should be close to one. In our analysis, we identified these traits with the possession of powers or abilities that exceed ordinary human abilities. For the most part, these equated with quasi-supernatural powers, though abilities at the extreme end of standard human capacities were also included. Analysis of the whole population of characters showed the median number of minimally counterintuitive traits for superheroes to be $1(N=3,178, I Q R=3)$, for heroes to be $1(N=2,665, I Q R=3)$, supervillains to be $2(N=459, I Q R=4)$ and villains to be $3(N=317, I Q R=3.27)$ (figure 7$)$. A Kruskal-Wallis test was used to evaluate the hypothesis that superheroes would exhibit minimally counterintuitive traits to a greater extent than other populations; this indicated significant differences between populations, $H(3)=113.23, p<.001$. Post hoc pairwise 
comparison showed that significant differences between all populations (except for superheroes and villains) in the predicted direction-i.e., superheroes had more counterintuitive traits than heroes and less than supervillains. For the top 100 characters, the median number of powers for superheroes was $5.1(I Q R=5.5)$, for heroes $2.72(I Q R=7.58)$, for supervillains $3(I Q R=6.56)$ and for villains $2.75(\mathrm{IQR}=5)$ (figure 8). A Kruskal Wallis test showed there to be significant differences between populations, $H(3)=15.07, p=.02$; post hoc pairwise testing indicated that there existed significant differences in the predicted direction between superheroes and heroes, on the one hand, and superheroes and villains, on the other. In this regard, the prosocial agents in the entire population of characters were more minimally counterintuitive relative to the antisocial characters (though they exhibited no internal differences); against this, the top 100 characters showed the alter-ego populations (superheroes and supervillains) to be less minimally counterintuitive than either heroes or villains. Thus, though the results for the entire population were consistent with superheroes being minimally counterintuitive, the match with predictions was weak; while results for the top 100 went entirely against the predictions.

\section{Conclusion}

Testing showed that, for all four predictions, the traits of the top 100 most popular characters confirmed our claims, with the exception of that made in relation minimally counterintuitive traits. Against this, analysis of the entire population only fully supported our claims when it came to the prediction concerning punitive prosociality, and offered only weak confirmation only with respect to minimally counterintuitive traits. Our view is that these results establish three of our four basic claims that the four predicted traits are central to the understanding of why comic-book superheroes emerged as a topic of cultural elaboration. 
When it comes to our motivating supposition - the claim that comic-book fabulation is a cognitive response to the pressures of large-group sociality—we are similarly sanguine about our hypothesis. In particular, we note that our study has important parallels with the large body of evidence that links the emergence of moralizing 'high gods' with the rise of complex social institutions and large groups (Bourrat et al., 2011; Peregrine, 1996; Roes \& Raymond, 2003; Shariff, Norenzayan, \& Henrich, 2009). No doubt, this raises the question of why comic-books and their cognates only emerged in the twentieth century, given that high gods can be traced back to the earliest cities. However, there is evidence to suggest that anxiety about punishment increases in situations where religiosity has a low cognitive salience (Laurin, Shariff, Henrich, \& Kay, 2012). Here, the idea is that not being able to rely on a supernatural figure to punish the guilty means that one must rely on oneself or other secular punishers instead. Thus, the decline in religiosity in western countries from the nineteenth century onwards (Bruce, 2006) may well have brought with it an increased concern with secular mechanisms of punishment and monitoring. If so, then comic-book superheroes neatly satisfy this need by embodying the traits associated with many divine punishers, but 'naturalising' these in a quasi-rational way. Nevertheless, we do acknowledge that, while these ideas point to intriguing ways of understanding how universally distributed modes of cognition may interact with local historical circumstances, they must, of necessity, remain speculative.

Equally, we concede that one deficiency in our analysis is the extent to which it relies upon proxies for data, when more fine-grained results would result from standard qualitative analysis. This is especially so when it comes to quasi-omniscience and minimally counterintuitive traits. Because these traits are categorical rather than numerical in character, no numerical metric is likely to perfectly align with their presence. Consider, for instance, minimally counterintuitive traits: while powers can certainly form part of what it means to be 
minimally counterintuitive, it is not at all obvious whether they should be treated as an aggregate ('Superman is a person who violates physical laws') or as a collection of individual violations ('Superman is a person who can fly, who can see through solid objects, who has super-strength ...'). We chose the latter option, though it might well be that the former better reflects intuitive ideas, with the result that our failure to conform their presence is an artefact of our methodological decisions. Or, it may well be that the concept is itself inherently imprecise, and that is needs to be reformulated along the lines suggested by other authors (Barrett, 2008; Gonce, Upal, Slone, \& Tweney, 2006; Norenzayan et al., 2006; Tweney, Upal, Gonce, Slone, \& Edwards, 2006).

With these problems so foregrounded, it is maybe also worth making an aside concerning how the quantitative treatment of qualitative data might be improved. In the present study, we were fortunate to have access to two comprehensive, frequently updated wikis that transformed qualitative content into highly structured data. In this, our situation was analogous to the empirical social sciences, where databases like the HRAF, the Standard Cross Cultural Sample and others allow for statistical analyses to be performed on the distribution of cultural and social characteristics. However, this is unusual: very few fictional genres have been subjected to this kind of treatment, with the result that it is often impossible to extend claims with any reliability. Indeed, this may help explain the unsatisfactory state of disciplines like literary studies, where polemical claims are often made about genres, periods and authors on the basis of statistically inadmissible evidence. (See Carney, Wlodarski, \& Dunbar (2014) for an experimental approach to literary questions.) For this reason, we suggest that one important future activity for practitioners of the humanities and social sciences might involve creating, so to speak, a HRAF of the human fabulation-a comprehensive database that details the nature, scope, outcome and scale of how human beings represent themselves as acting in the virtual worlds that they create. Of course, such 
an undertaking, like its real-world equivalents, would take sustained effort to design, bring about and maintain. Nevertheless, when one considers what this compendium might tell us about the relation between mind and culture, there can be no doubting that it would reward the investment made in creating it.

To close, our goal in the present study will have been achieved if we have demonstrated two things. Firstly, that variation in the representation of comic-book characters exhibits regularities that are partially driven by cognitive factors; and secondly, that these factors can be related to the problems of assorting in large groups. Though it is obviously impossible to unequivocally show either of these to be the case, we nevertheless submit that the data gathered and analyses performed support the claims that we have made both here and in previous work. If this is indeed so, then our conviction is that popular culture may well yet offer a valuable adjunct to religion as a forum for exploring how the human cognitive endowment mediates itself through culture. 
Works Cited

Atkinson, Q. D., \& Bourrat, P. (2011). Beliefs about God, the afterlife and morality support the role of supernatural policing in human cooperation. Evolution and Human Behavior, $32(1), 41-49$.

Atran, S. (2002). In Gods We Trust: The Evolutionary Landscape of Religion. Oxford: Oxford University Press.

Atran, S., \& Norenzayan, A. (2002). Cognitive and Emotional Processes in the Transmission of Natural and Non-Natural Beliefs. In M. Schaller \& C. Crandall (Eds.), The Psychological Foundations of Culture (pp. 149-169). Nillsdale NJ: Erlbaum.

Barrett, J. (2008). Coding and Quantifying Counterintuitiveness in Religious Concepts: Theoretical and Methodological Reflections. Method \& Theory in the Study of Religion, 20(4), 308-338. doi:10.1163/157006808X371806

Barrett, J., \& Nyhof, M. (2001). Spreading Non-natural Concepts: The Role of Intuitive Conceptual Structures in Memory and Transmission of Cultural Materials. Journal of Cognition and Culture, 1(1), 69-100. doi:10.1163/156853701300063589

Barrett, J., \& Reed, E. (2011). The cognitive science of religion. The Psychologist, 24(4), $252-255$.

Bendor, J., \& Swistak, P. (2001). The Evolution of Norms. American Journal of Sociology, $106(6), 1493-1545$.

Bering, J., \& Johnson, D. (2005). "O Lord ... You Perceive my Thoughts from Afar": Recursiveness and the Evolution of Supernatural Agency. Journal of Cognition and Culture, 5(1), 118-142.

Berlyne, D. (1970). Novelty, complexity, and hedonic value. Perception \& Psychophysics, 8, 279-286. Retrieved from http://link.springer.com/article/10.3758/BF03212593

Bettencourt, B. A., Dill, K. E., Greathouse, S. a., Charlton, K., \& Mulholland, A. (1997). Evaluations of Ingroup and Outgroup Members: The Role of Category-Based Expectancy Violation. Journal of Experimental Social Psychology, 33(3), 244-275. doi:10.1006/jesp.1996.1323

Bhaba, H. K. (1990). Nation and Narration. (H. K. Bhaba, Ed.). London: Routledge.

Bilke, S., \& Peterson, C. (2001). Topological properties of citation and metabolic networks. Physical Review E, 64(3), 036106. doi:10.1103/PhysRevE.64.036106

Bourrat, P., Atkinson, Q. D., \& Dunbar, R. I. M. (2011). Supernatural Punishment and Individual Social Compliance across Cultures. Religion, Brain \& Behavior, 1(2), 119 134. 
Boyer, P. (1999). Cognitive Tracks of Cultural Inheritance: How Evolved Intuitive Ontology Governs Cultural Transmission. American Anthropologist, 100(4), 876-889.

Boyer, P. (2001). Religion Explained: The Evolutionary Origins of Religious Thought. New York: Basic Books.

Boyer, P., \& Ramble, C. (2001). Cognitive templates for religious concepts: cross-cultural evidence for recall of counter-intuitive representations. Cognitive Science, 25(4), 535564. doi:10.1207/s15516709cog2504_2

Brown, J. A. (1992). Comic Book Fandom and Cultural Capital. Journal of Popular Culture, $30(4), 13-31$.

Bruce, S. (2006). Secularization and the Impotence of Individualized Religion. Hedgehog Review, 8(1-2), 35-45. Retrieved from http://www.iascculture.org/THR/archives/AfterSecularization/8.12EBruce.pdf

Bruner, J. (1991). The narrative construction of reality. Critical Inquiry, 18(1), 1-21.

Byrne, R. W., \& Corp, N. (2004). Neocortex size predicts deception rate in primates. Proceedings of the Royal Society B, 271(1549), 1693-9. doi:10.1098/rspb.2004.2780

Carlos, M. L. (1973). Fictive Kinship and Modernization in Mexico: A Comparative Analysis. Anthropological Quarterly, 46(2), 75-91.

Carney, J. (2014). Supernatural Intuitions and Classic Detective Fiction: A Cognitivist Appraisal. Style, 48(3), 203-218.

Carney, J., Dunbar, R., Dávid-Barrett, T., Machin, A., \& Júnior, M. S. (2014). Social psychology and the comic-book superhero: A Darwinian approach. Philosophy and Literature, 38(1A), 195-215. doi:10.1353/phl.2014.0019

Carney, J., Wlodarski, R., \& Dunbar, R. (2014). Inference or Enaction? The Impact of Genre on the Narrative Processing of Other Minds. PLOS ONE, 9(12), e114172. doi:10.1371/journal.pone.0114172

Carsten, J. (2000). Cultures of Relatedness: New Approaches to the Study of Kinship. (J. Carsten, Ed.). Cambridge University Press.

Chatters, L. M., Taylor, R. J., \& Jayakody, R. (1994). Fictive Kinship Relations in Black Extended Families. Journal of Comparative Family Studies, 25(3), 297-312.

Clasen, M. (2012). Monsters Evolve: A Biocultural Approach to Horror Stories. Review of General Psychology, 16(2), 222-229. doi:10.1037/a0027918

Dávid-Barrett, T., \& Dunbar, R. (2012). Cooperation, behavioural synchrony and status in social networks. Journal of Theoretical Biology, 308, 88-95. doi:10.1016/j.jtbi.2012.05.007 
Dávid-Barrett, T., \& Dunbar, R. (2013). Processing power limits social group size: computational evidence for the cognitive costs of sociality. Proceedings of the Royal Society B, 280(June), 1-7. Retrieved from http://rspb.royalsocietypublishing.org/content/280/1765/20131151.short

Dissanayake, E. (2000). Art and Intimacy: How the Arts Began. Seattle: University of Washington Press.

Dunbar, R. (1992). Neocortex size as constraint on group size in primates. Journal of Human Evolution, 20(1), 469-493.

Dunbar, R. (1993). Coevolution of neocortical size, group size and language in humans. Behavioral and Brain Sciences, 16, 681-735. doi:10.1017/S0140525X00032325

Dunbar, R. (1996). Grooming, Gossip, and the Evolution of Language. London: Faber \& Faber.

Dunbar, R. (1998). The Social Brain Hypothesis. Evolutionary Anthropology: Issues, News, and Reviews, 6(5), 178-190. doi:10.1002/(SICI)1520-6505(1998)6:5<178::AIDEVAN5>3.3.CO;2-P

Dunbar, R., \& Shultz, S. (2007). Evolution in the social brain. Science (New York, N.Y.), 317(5843), 1344-7. doi:10.1126/science.1145463

Eco, U. (1972). The Myth of Superman. Diacritics, 2(1), 14-22.

Eshel, I., Sansone, E., \& Shaked, A. (1999). The emergence of kinship behavior in structured populations of unrelated individuals. International Journal of Game Theory, 28(4), 447463. doi:10.1007/s001820050119

Fauconnier, G., \& Turner, M. (2002). The Way We Think: Conceptual Blending and the Mind's Hidden Complexities. New York: Basic Books.

Fehr, E., \& Fischbacher, U. (2004). Third-party punishment and social norms. Evolution and Human Behavior, 25(2), 63-87. doi:10.1016/S1090-5138(04)00005-4

Flack, J. C., Girvan, M., de Waal, F. B. M., \& Krakauer, D. C. (2006). Policing stabilizes construction of social niches in primates. Nature, 439(7075), 426-9. doi:10.1038/nature04326

Gonçalves, B., Perra, N., \& Vespignani, A. (2011). Modeling users' activity on twitter networks: validation of Dunbar's number. PloS One, 6(8), e22656. doi:10.1371/journal.pone.0022656

Gonce, L., Upal, M. A., Slone, D. J., \& Tweney, D. R. (2006). Role of Context in the Recall of Counterintuitive Concepts. Journal of Cognition and Culture, 6(3), 521-547. doi:10.1163/156853706778554959

Gould, R. V. (1993). Collective Action and Network Structure. American Sociological Review, 58(2), 182-196. 
Hamilton, M., Milne, B., Walker, R., Burger, O., \& Brown, J. (2007). The complex structure of hunter-gatherer social networks. Proceedings. Biological Sciences / The Royal Society, 274(1622), 2195-202. doi:10.1098/rspb.2007.0564

Hamilton, W. D. (1964). The genetical evolution of social behaviour. Journal of Theoretical Biologyiology, 7(1), 1-16. Retrieved from http://www.ncbi.nlm.nih.gov/pubmed/5875341

Harris, C., \& Alexander, A. (1998). Theorizing Fandom: Fans, Subculture and Identity. (C. Harris \& A. Alexander, Eds.). New York: Hampton Press.

Henrich, J., McElreath, R., Barr, A., Ensminger, J., Barrett, C., Bolyanatz, A., ... Ziker, J. (2006). Costly punishment across human societies. Science (New York, N.Y.), 312(5781), 1767-70. doi:10.1126/science.1127333

Hill, R. A., \& Dunbar, R. (2003). Social network size in humans. Human Nature, 14(1), 5372.

Hove, M. J., \& Risen, J. L. (2009). It's All in the Timing: Interpersonal Synchrony Increases Affiliation. Social Cognition, 27(6), 949-960. doi:10.1521/soco.2009.27.6.949

Humphrey, N. K. (1976). The social function of intellect. In P. P. G. Bateson \& R. A. Hinde (Eds.), Growing Points in Ethology (pp. 303-317). Cambridge: Cambridge University Press.

Ibsen, C., \& Klobus, P. (1972). Fictive kin term use and social relationships: Alternative interpretations. Journal of Marriage and the Family, 34(4), 615-620. Retrieved from http://www.jstor.org/stable/350312

Jarett, C. (2011). The Lure of Horror. The Psychologist, 24(11), 812-815.

Johnson, D., \& Krüger, O. (2004). The God of Wrath: Supernatural Punishment and the Evolution of Cooperation. Political Theology, 2, 159-176.

Killworth, P., Bernard, H. R., \& McCarty, C. (1984). Measuring Patterns of Acquaintanceship. Current Anthropology, 25(4), 381-397. Retrieved from http://www.jstor.org/stable/2742900

Kleefeld, S. (2009). Comic Book Fanthropology HC. Hamilton OH: Eight Twenty Press.

Lakoff, G. (2002). Moral Politics: How Liberals and Conservatives Think. Chicago: University of Chicago Press.

Launay, J., Dean, R. T., \& Bailes, F. (2013). Synchronization can influence trust following virtual interaction. Experimental Psychology, 60(1), 53-63. doi:10.1027/1618$3169 / \mathrm{a} 000173$

Laurin, K., Shariff, A. F., Henrich, J., \& Kay, A. C. (2012). Outsourcing Punishment to God: Beliefs in Divine Control Reduce Earthly Punishment. Proceedings of the Royal Society B, 279(1741), 3272-81. doi:10.1098/rspb.2012.0615 
Lévi-Strauss, C. (1955). The Structural Study of Myth. The Journal of American Folklore, 68(270), 428-444.

Mac Carron, P., \& Kenna, R. (2012). Universal properties of mythological networks. EPL (Europhysics Letters), 99(2), 28002. doi:10.1209/0295-5075/99/28002

Mac Carron, P., \& Kenna, R. (2013). Viking sagas: Six degrees of Icelandic separation. Significance, December, 12-17.

Morin, O. (2012). When Does Psychology Drive Culture? In E. Slingerland \& M. Collard (Eds.), Creating Consilience: Integrating the Sciences and the Humanities (pp. 179193). Oxford: Oxford University Press.

Nations, U. (2014). World Urbanization Prospects: The 2014 Revision.

Newman, M., \& Park, J. (2003). Why social networks are different from other types of networks. Physical Review E, 68(3), 036122. doi:10.1103/PhysRevE.68.036122

Norenzayan, A., Atran, S., Faulkner, J., \& Schaller, M. (2006). Memory and mystery: the cultural selection of minimally counterintuitive narratives. Cognitive Science, 30(3), 531-53. doi:10.1207/s15516709cog0000_68

Pedersen, E. J., Kurzban, R., \& McCullough, M. E. (2013). Do humans really punish altruistically? A closer look. Proceedings of the Royal Society B, 280(March), 1-8.

Peregrine, P. (1996). The Birth of the Gods Revisited: A Partial Replication of Guy Swanson's (1960) Cross-Cultural Study of Religion. Cross-Cultural Research, 30(1), 84-112. doi:10.1177/106939719603000104

Piazza, J., Bering, J., \& Ingram, G. (2011). “Princess Alice is watching you”: children's belief in an invisible person inhibits cheating. Journal of Experimental Child Psychology, 109(3), 311-20. doi:10.1016/j.jecp.2011.02.003

Roes, F. L., \& Raymond, M. (2003). Belief in Moralizing Gods. Evolution and Human Behavior, 24, 126-135.

Salmon, C. (2005). Crossing the Abyss: Erotica and the Intersection of Evolutionary Psychology and Literary Studies. In D. S. Wilson \& J. Gottschall (Eds.), The Literary Animal: Evolution and the Nature of Narrative (pp. 244-257). Evanston IL: Northwestern University Press.

Shariff, A., Norenzayan, A., \& Henrich, J. (2009). The Birth of High Gods: How the Cultural Evolution of Supernatural Policing Agents Influenced the Emergence of Complex, Cooperative Human Societies, Paving the Way for Civilization. In M. Schaller, A. Norenzayan, S. Heine, T. Yamagishi, \& K. T (Eds.), Evolution, Culture, and the Human Mind (pp. 117-136). Mahwah NJ: Lawrence Erlbaum.

Siegel, D. A. (2009). Social Networks and Collective Action. American Journal of Political Science, 53(1), 122-138. 
Sigmund, K., Hauert, C., \& Nowak, M. a. (2001). Reward and punishment. Proceedings of the National Academy of Sciences of the United States of America, 98(19), 10757-62. doi:10.1073/pnas.161155698

Somers, M. (1994). The narrative constitution of identity: A relational and network approach. Theory and Society, 23(5), 605-649. Retrieved from http://www.springerlink.com/index/k7832367t271u7k1.pdf

Sosis, R. (2004). The Adaptive Value of Religious Ritual: Rituals Promote Group Cohesion by Requiring Members to Engage in Behavior that is too Costly to Fake. American Scientist, 92(2), 166-172.

Sosis, R. (2005). Does Religion Promote Trust? The Role of Signaling, Reputation, and Punishment. Interdisciplinary Journal of Research on Religion, 1, 1-30.

Sperber, D. (1975). Rethinking Symbolism. Cambridge: Cambridge University Press.

Sperber, D. (2006). Why a deep understanding of cultural evolution is incompatible with shallow psychology. In N. J. Enfield \& S. C. Levinson (Eds.), Roots of Human Sociality: Culture, Cognition and Interaction (pp. 431-452). Oxford: Berg Publishers.

Sperber, D., \& Wilson, D. (1995). Relevance: Communication \& Cognition. Oxford: Blackwell Publishing.

Tweney, R., Upal, M. A., Gonce, L., Slone, D. J., \& Edwards, K. (2006). The Creative Structuring of Counterintuitive Worlds. Journal of Cognition and Culture, 6(3), 483498. doi:10.1163/156853706778554904

Usdiken, B., \& Pasadeos, Y. (1995). Organizational Analysis in North America and Europe: A Comparison of Co-citation Networks. Organization Studies, 16(3), 503-526. doi:10.1177/017084069501600306

Wellman, B. (2012). Is Dunbar's number up? British Journal of Psychology, 103(2), 174-6; discussion 180-2. doi:10.1111/j.2044-8295.2011.02075.x

Whitehouse, H. (2004). Modes of Religiosity: A Cognitive Theory of Religious Transmission: A Cognitive Theory of Religious Transmission (p. 208). Berkeley: AltaMira Press.

Williamson, J. G. (2002). Coping with City Growth During the British Industrial Revolution. Cambridge: Cambridge University Press.

Wright, B. W. (2001). Comic Book Nation: The Transformation of Youth Culture in America. Baltimore MD: JHU Press.

Zhou, W.-X., Sornette, D., Hill, R. a, \& Dunbar, R. I. M. (2005). Discrete hierarchical organization of social group sizes. Proceedings. Biological Sciences / The Royal Society, 272(1561), 439-44. doi:10.1098/rspb.2004.2970

Zunshine, L. (2011). What to Expect When You Pick Up a Graphic Novel. SubStance, 1(6), $114-134$. 
Zunshine, L. (2012). Getting Inside Your head: What Cognitive Science Can Tell Us About Popular Culture. Baltimore MD: JHU Press. 
Figure 1: Punitive prosociality for entire population

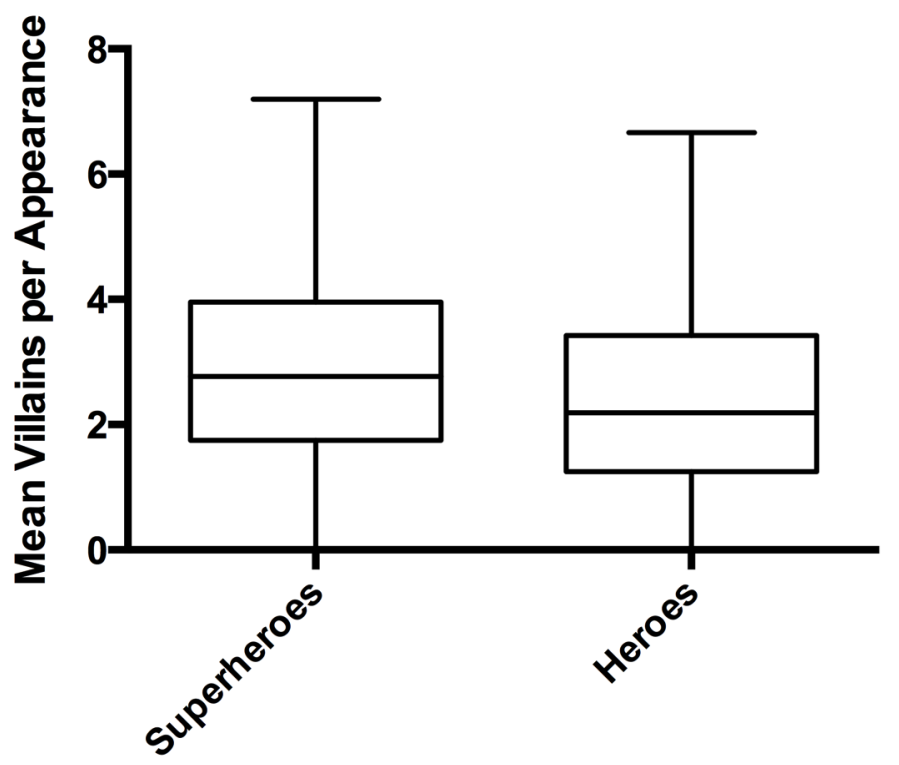

Character Type

Figure 2: Punitive prosociality for top 100 characters

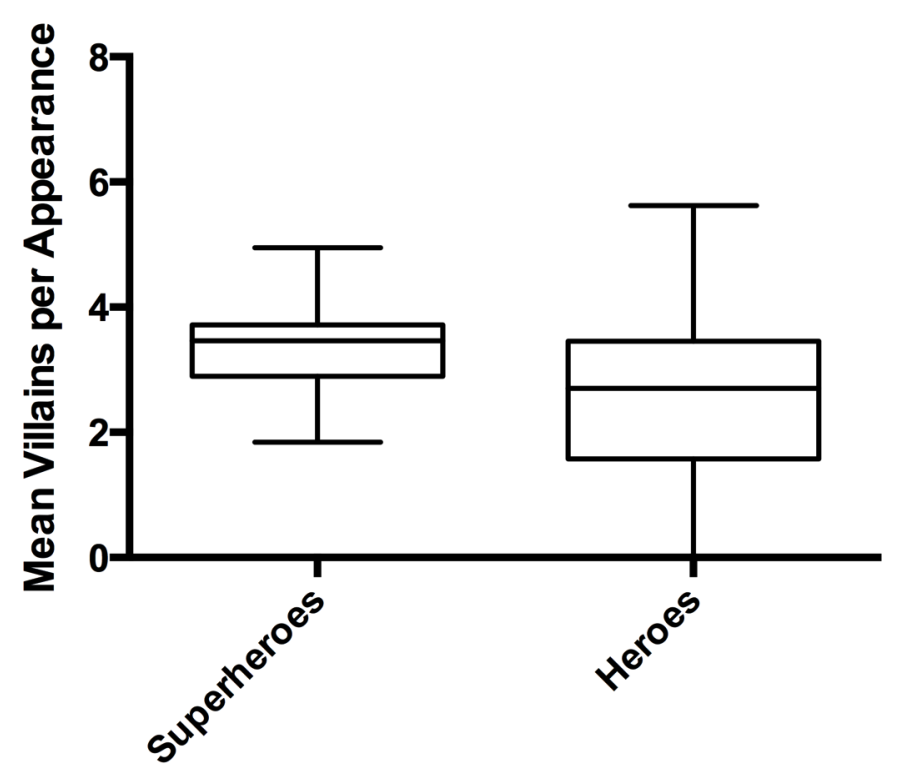

Character Type 
Figure 3: Quasi-omniscience for entire population

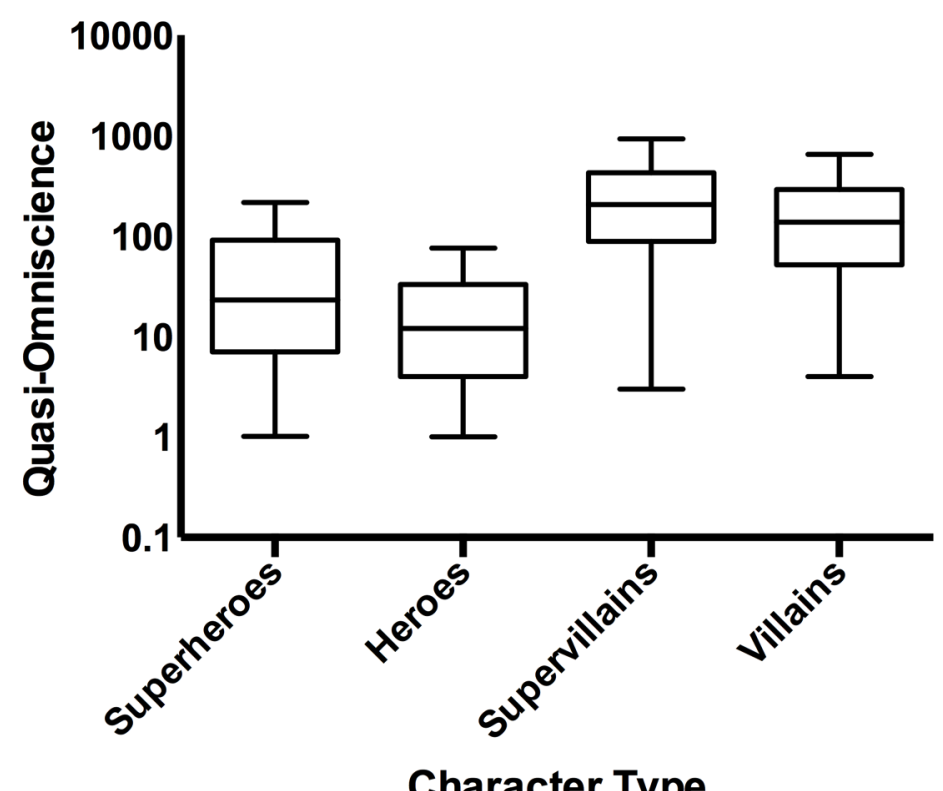

Figure 4: Quasi-omniscience for top 100 characters

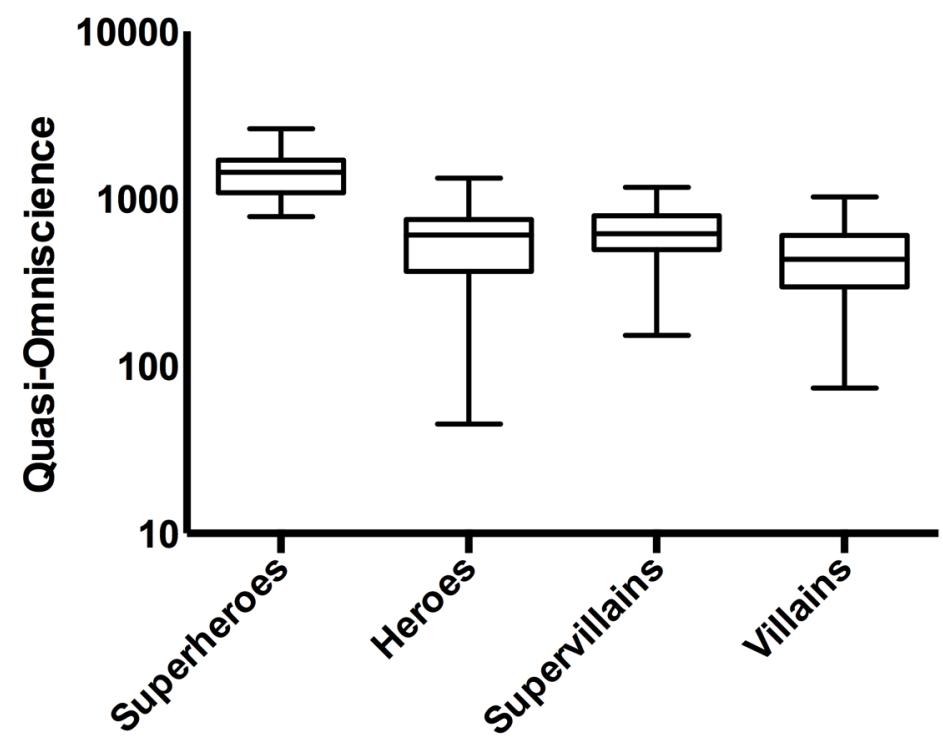

Character Type 
Figure 5: Kin-signalling strength for entire population

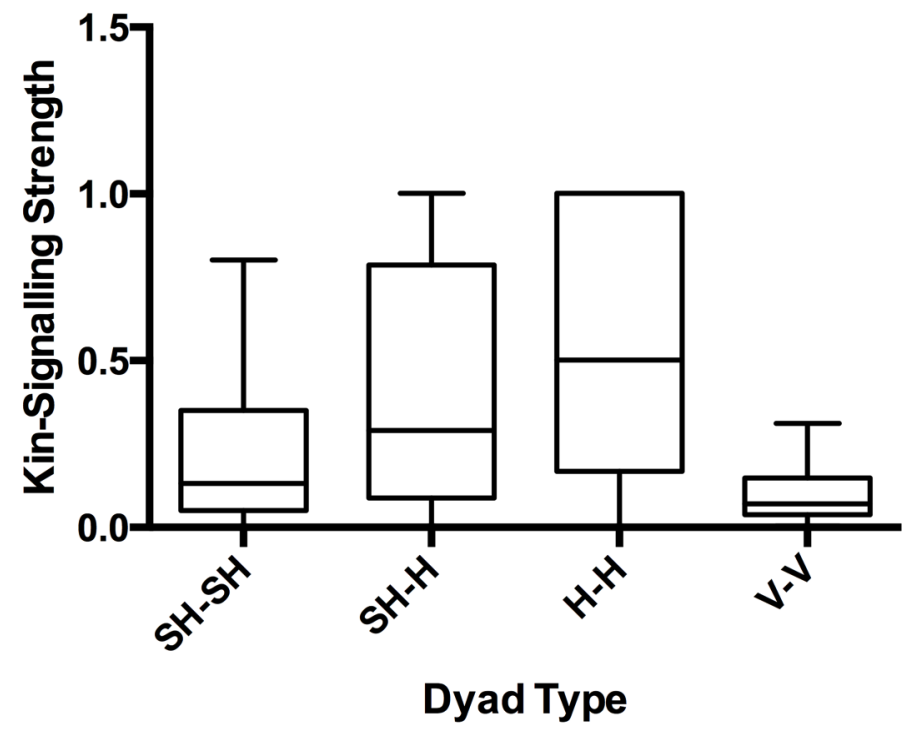

Figure 6: Kin-signalling strength for top 100 characters

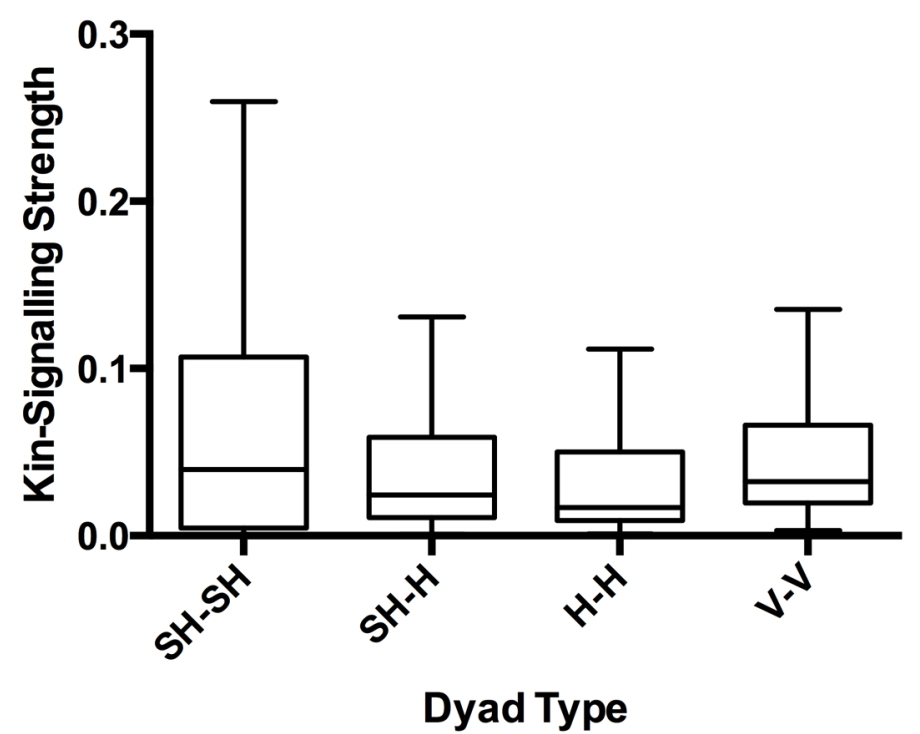


Figure 7: Number of powers for entire population

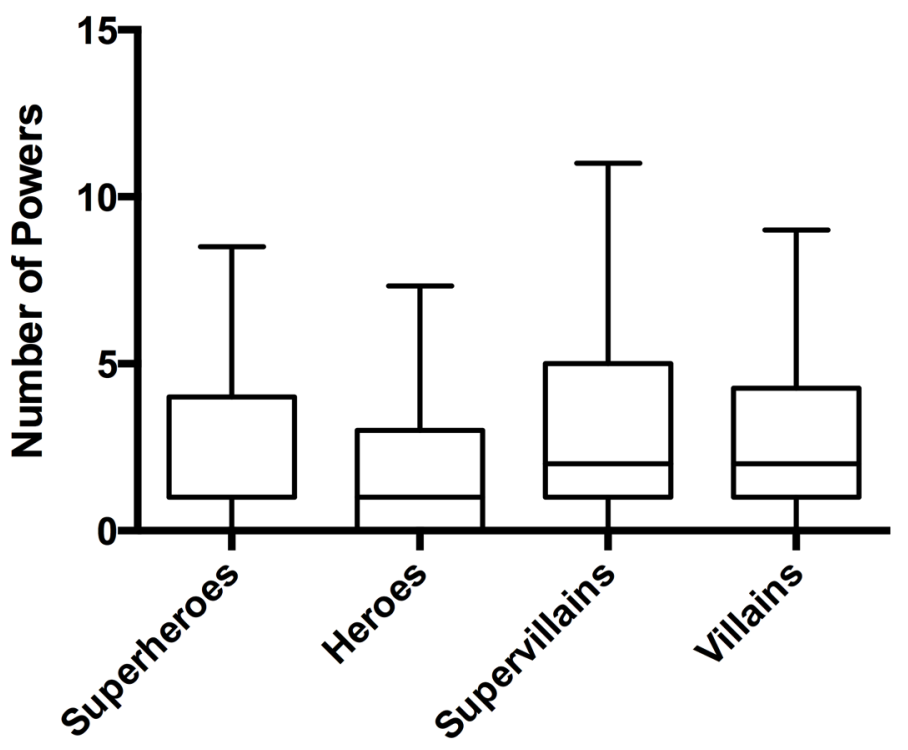

Character Type

Figure 8: Number of powers for top 100 characters

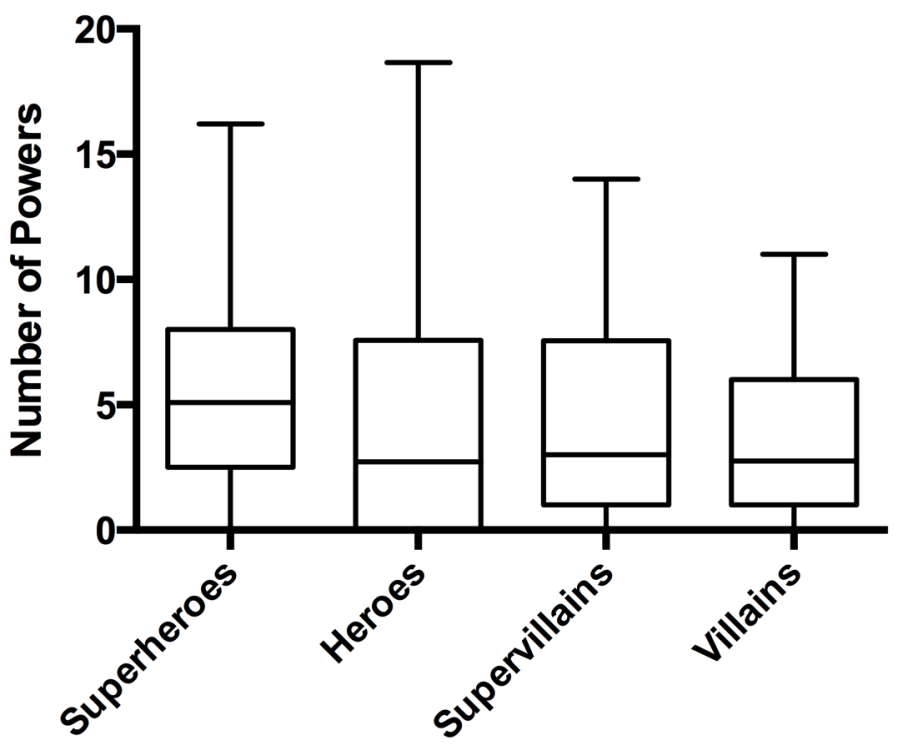

Character Type 